\title{
ESPIRITUALIDAD Y AUTOCONCIENCIA EXISTENCIAL EN TUGENDHAT
}

\author{
SPIRITUALITY AND EXISTENTIAL SELF-CONSCIOUSNESS \\ IN TUGENDHAT \\ José V. Bonet-Sánchez
}

\begin{abstract}
RESUMEN
La filosofía de la religión y la mística del último Tugendhat se inserta en el centro de su etapa antropológica, pero guarda relación con toda su obra precedente. Las raíces antropológicas de la espiritualidad se hallan en la autoconciencia práctica o existencial, que se refiere al conjunto de nuestra vida y está expuesta — more heideggeriano- a la contingencia. A esta responden, según Tugendhat, la religión, con su creencia en seres espirituales (que él rechaza enérgicamente), y diversas formas de místicas orientales impersonales, como el budismo y el tao, que atemperan la voracidad de un yo egocéntrico. El artículo analiza la teorización tugendhatiana de ambos fenómenos y discute su argumento en pro del ateísmo, por mor de la "honestidad intelectual", lo mismo que su pretensión de tomar las doctrinas místicas únicamente en su vertiente práctico-existencial.
\end{abstract}

PALABRAS CLAVE: Antropología filosófica. Ateísmo. Contingencia. Egocentricidad. Existencialismo. Mística. Religión. Sein und Zeit.

\section{ABSTRACT}

Philosophy of religion and mysticism of the latest Tugendhat belong to the centre of his anthropological period but are related to the whole of his previous work. The anthropological roots of spirituality lie in practical or existential self-consciousness, which refers to our life in its entirety and is exposed - Heideggerian more - to contingency. According to Tugendhat, contingency elicits religion, with its beliefs in spiritual beings (that he strongly rejects), and several forms of impersonal oriental mysticisms, such as Buddhism and Tao, which mitigate the voracity of an egotistical self. This paper analyses the Tugendhatian theorization of both phenomena and dicusses his argument in favour of atheism for the sake of "intellectual honesty", as well as his claim of adoptng mystical doctrines but only from their practical-existential aspect.

KEYWORDS: Atheism. Contingency. Egocentricity. Existentialism. Mysticism. Philosophical Antropology. Religion. Sein und Zeit. 


\section{El giro antropológico Del Último TugendHat}

En el año 2000, Tugendhat nos sorprendió, en la biblioteca de Valencia, con un breve curso de antropología filosófica, decía él, escrito en castellano, que culminaba con una conferencia titulada "Las raíces antropológicas de la religión y la mística" (Raíces en lo sucesivo). El tema, que seguirá abordando en escritores posteriores, guarda relación con el conjunto de su trayectoria e incluso con su biografía ${ }^{1}$, en la que existe una significativa relación de contigüidad temporal entre la preocupación por la religión y la mística, por una parte, y la lectura o relectura del Heidegger más existencialista, por otra.

A los efectos que aquí nos interesan, la vida de Tugendhat comienza cuando su muy adinerada familia judía, escapando del nazismo, abandona su casa de Brno, diseñada por Mies van der Rohe, y termina recalando en Venezuela. Ernesto - como empezó a llamarse allí, ya para el resto de su vida—, que entonces contaba 11 o 12 años, comienza a tener experiencias místicas y quería ser rabino. Su padre reaccionó contratando un preceptor que instruyó al joven en el pensamiento de Freud; y de sus relatos de aquella experiencia se infiere que debió incidir especialmente en la crítica de la religión y el monoteísmo, dejando en él una huella imborrable. Paralelamente, su madre y una amiga le regalarían Sein und Zeit, que a los 15 años Ernesto había leído ya dos veces, y otros cursos anuales de Heidegger de la misma época. Poco después, ya en la Universidad de Stanford, Tugendhat participó como estudiante en algunos seminarios sobre mística, tras los cuales interrumpió durante cuatro décadas su contacto intelectual con este asunto.

En los años 50 pasó Tugendhat a estudiar en Friburgo con Heidegger. A finales de la década comenzará a desplegar una obra que existe consenso en agrupar en cuatro ciclos o campos temáticos ${ }^{2}$ que, a lo largo del tiempo, se despliegan de forma más o menos sucesiva y, por comodidad, podemos denominar etapas. Paso a recordarlas, subrayando los hitos de las tres primeras que guardan una relación más estrecha con la antropología de Tugendhat y su filosofía de la espiritualidad.

La primera etapa, presidida por el influjo de Heidegger, culmina en Der Wahrheitsbegriff bei Husserl y Heidegger (1967). En la segunda, Tugendhat abandona expresamente el método fenomenológico $(1970 ; 1976)$ y lo sustituye por un análisis

\footnotetext{
${ }^{1}$ Tugendhat 1992a, pp. 7-18; Suárez Crothers 2005; Hermann 2007; Bonet 2013, pp. 27 ss. Para estos y algunos otros detalles, me apoyo también en mis conversaciones y correspondencia con el autor.

2 Thies (2009/2010, 337 s.), Bonet (2013, pp. 27-59).
} 
lingüístico cuya mayor originalidad consiste en la interpretación analítico-lingüística de conceptos clave de la ontología heideggeriana, como ser, existencia y verdad. A este ciclo pertenecen los libros más brillantes del autor, Vorlesungen zur Einfübrung in die sprachanalytische Philosophie (1976) y Autoconciencia y autodeterminación (1979/1993a) ${ }^{3}$. La tercera etapa consiste, más que en una revolución, en un abandono ${ }^{4}$ : Tugendhat deja de lado la filosofía teórica — de hecho, todo aquello que tenía que ver con la metafísica - para dedicarse a la ética y, al mismo tiempo, implicarse al máximo en debates políticos tan vivos, en el Berlín de los 80, como el del pacifismo nuclear $\left(1988^{2}\right)$. En realidad, la fundamentación de la ética, que aborda en tres libros (1984; 1993b; 1998) y un sinfín de artículos, es un tema que ya nunca abandonará. Y esa es una de las razones de que resulte impreciso hablar de etapas. Además, uno de los motivos del viraje antropológico, que representa la cuarta y última, es precisamente el de buscar una solución diferente a la fundamentación de la moral, relacionándola con la función biológica que aquella ha podido cumplir en la evolución ${ }^{5}$. Pero había también otros motivos para ese viraje. ¿Cuáles?

Recobremos la biografía del autor en 1992, cuando se jubila en la Universidad Libre de Berlín y emprende un proyecto personal que le lleva otra vez a Latinoamérica. Mientras explica allí sus Lecciones de ética de 1993 en distintos cursos y países, es invitado a disertar sobre el Heidegger de Ser y tiempo $0^{6}$. Al concluir el proyecto personal con 66 años, se encuentra con que lo único que puede ya esperar es la muerte y filosofa sobre ello ${ }^{7}$. Esta vez no se trata de abordar los conceptos principales de la ontología heideggeriana, sino de aprovechar sus observaciones particulares sobre los temas más existenciales o, como Tugendhat dirá ahora, antropológicos, sintonizando así con la idea de antropología filosófica

\footnotetext{
3 Uso la barra / para hacer referencia a la traducción. Aunque Tugendhat escribe más en alemán, también redactó originalmente algunos trabajos en castellano o inglés. Cuando transcriba la versión española, la citaré en primer lugar, como hago a menudo con la traducción de Egocentricidad de Suárez Crothers.

4 Tugendhat empleó esta palabra en la primera carta que crucé con él.

5 Tugendhat 2001, pp. 199-224 / 2002, pp. 135-158; 2007a, pp. 136-155 / 2007b, pp. 115-135 (como otros artículos de la serie, este fue redactado en castellano). El recurso a fenómenos antropológicos asomaba ya, aquí y allá, en Tugendhat 1998.

6 Tugendhat 1992, pp. 108-135; y 2001, pp. 11-26 / 2002, pp. 231-244.

7 "Me encontré horrorizado esperando la muerte", declara a Hermann (2007). De ahí surge un artículo de 1996 (Tugendhat 2002, pp. 161-181) que fue de hecho el punto de partida de Egocentricidad (2003, p. 99 nota / 2004, p. 112 nota) y volvió a retomar en Antropología (2007a/2007b).
} 
que, en los años 20, formularon en Alemania Scheler, Plessner y Gehlen, y que, en opinión de nuestro autor, latía también, enmascarada, en Ser y tiempo (2002, pp. 202-205). Tugendhat concibe la antropología filosófica como una forma débil de filosofía primera y pugna por insertar en ella sus propios descubrimientos filosóficos de los dos ciclos precedentes (el analítico y el ético-político), e incluso algún tema capital de Der Wabrheitsbefriff, como el que ahora etiqueta como honestidad intelectual. Esta última reconversión o reconstrucción despunta en un ciclo de escritos de 1998-2000, a los que me referiré en bloque como artículos o trabajos "fundacionales", y dará lugar a dos libros suyos más: Egocentricidad y mística (2003), el texto que sistematiza con un argumento unitario la nueva perspectiva de conjunto del autor, y Antropología en vez de metafísica ${ }^{9}$, una colección de artículos de temática antropológica explícita y bastante unitaria.

A mi modo de ver, toda esta última fase o etapa conecta sobre todo con $A u$ toconciencia, el libro más antropológico de las etapas precedentes, del que surge su concepción de autoconciencia práctica, base del concepto de egocentricidad del libro homónimo. En lo cual debe entenderse que antropológico significa, como veremos, existencial. En realidad, una parte de este último ciclo podría verse como un último ajuste de cuentas con Heidegger, rayano a veces en la ingratitud ${ }^{10}$. Pero ese no es el caso de los diversos textos de Tugendhat sobre religión y mística ${ }^{11}$,

8 Se visualiza esto perfectamente en Problemas (Tugendhat 2002) mejor que en las compilaciones alemanas de 2001 y 2007a, cada una de las cuales incluye solo uno de los tres trabajos fundacionales.

9 Tugendhat 2007a/2007b. En lo sucesivo, mencionaré el libro como Antropología. Usaré también para los libros correspondientes las abreviaturas de Der Wabrbeitsbegriff, Vorlesungen zur Einführung, Autoconciencia y Egocentricidad.

10 Véase Hermann 2007.

11 Son cinco. El primero, Raíces (Tugendhat 2002, pp. 215-228), que no se publicaría después en alemán porque, llegado el momento de hacerlo, el autor había modificado su planteamiento. Y es que, como escribí en otra ocasión, Tugendhat convierte la retractación en un género filosófico-literario. Vienen después varios capítulos correspondientes de Egocentricidad y otros tres artículos: el Discurso de aceptación del premio Meister Eckhart ("Über Mystik. Vortrag...”) y el artículo "Über Religion", donde el autor admite haberse mostrado "más ambivalente", menos unilateral que en Egocentricidad. Ambos quedaron recogidos en Antropología (2007a, pp. 176 ss. y 191 ss. / 2007b, pp. 157 ss. y 173 ss.). Finalmente, "Spiritualität, Religion und Mystik", es el comentario de Tugendhat (2012) a un simposio sobre Mística, religión y honestidad intelectual organizado a raíz de Egocentricidad que, como se ve, es el texto capital. Los denominaré respectivamente, Discurso, Über Religion y Spiritualität. Yo diría que estos dos últimos representan la posición final del autor. 
que nada le deben a Heidegger y poco a Bergson (2012), Scheler (2009) o Jaspers (2012), que sí se ocuparon del asunto. Por supuesto, tampoco Tugendhat es deudor de Heidegger cuando plantea la pregunta por el ser del hombre desde una óptica comparativa con el modo de vivir de los animales no humanos, pensando en la función biológica o evolutiva de las estructuras analizadas.

\section{LENGUAJE Y AUTOCONCIENCIA PRÁCTICA}

Egocentricidad es, por los motivos apuntados, un libro ambicioso que Tugendhat publica con 73 años, concluyéndolo, según admitió luego, con cierta impaciencia. De ahí que resulte esquemático, denso, con demasiadas cartas sobre un tapete relativamente pequeño. Los primeros cuatro capítulos de Egocentricidad recogen los hilos de sus tres etapas anteriores que Tugendhat ve factible reunir ahora en un argumento antropológico que conduzca hasta el sentido existencial ${ }^{12}$ de la mística, que consiste en un retraimiento o distanciamiento de $\mathrm{si}^{13}$ - de la propia egocentricidad, como explicaremos_- En esta sección, me propongo simplificar ese argumento, reduciéndolo a sus pasos imprescindibles, basándome para ello en los trabajos paralelos del autor, sobre todo en Spiritualität. A la vez, ahondaré en el alcance de alguno de esos pasos recurriendo a los trabajos anteriores del autor de los que, en más de una ocasión, procede la idea.

Por cierto, que en Spiritualität Tugendhat no habla de raíces antropológicas, sino del modo en que religión y mística surgen de la "estructura de conciencia" del ser humano (2012, p. 161). Las dos fórmulas son equivalentes: las raíces antropológicas de la espiritualidad están en la estructura temporal y lingüística de la autoconciencia práctica humana. Pero la autoconciencia no es, al agudo juicio de Tugendhat, un fenómeno unitario. La filosofía moderna la equiparó con la forma de saber incuestionable que tiene el sujeto de sí mismo, de su yo. Es lo que Tugendhat llama autoconciencia epistémica inmediata, la cual, en realidad, no versa sobre el sujeto entero, como un todo, como pretendiera el idealismo, sino solo sobre las propias vivencias particulares, estados psicológicos conscientes como mi propio dolor o mi sensación de cansancio ${ }^{14}$.

12 Esta palabra corre las más de las veces por mi cuenta. Tugendhat la emplea poco.

13 Sobre la traducción del verbo alemán, zurücktreten, que es distinta en Tugendhat 2004 y 2007b, véase, la nota del traductor de 2004, p. 35.

14 Tugendhat 1979, pp. 27 s. / 1993a, pp. 23 s.; Bonet 2013, 146 s. 
En la $2^{\mathrm{a}}$ lección de Autoconciencia añade Tugendhat, inspirándose en el Strawson de Individuals, que tenemos además una autoconciencia epistémica mediata de predicados corporales que también un tercero nos podría atribuir, desde la perspectiva del observador; por ejemplo, cuando observo en el espejo que me han salido canas en el pelo. Distinta de ambas, y muchos menos tratada en la filosofía, es la autoconciencia práctica que Kierkegaard y Heidegger intentaron analizar, esto es, la relación emocional y volitiva con nosotros mismos, con nuestra propia existencia - la propia, la de cada quien-, que en cada una de nuestras acciones e inacciones tiene lugar de manera práctica. Es un hecho: todo ser humano se encuentra con que su propio ser no es otra cosa que lo que hace con él viviendo ${ }^{15}$. Es de este fenómeno, personal e intransferible, de donde surge el concepto de egocentricidad, al que Tugendhat llega mediante cierto circunloquio:

El sujeto del argumento de Egocentricidad es, en todo momento, quien dice "yo" (der "Ich" Sager). Tugendhat se refiere así de una forma económica al fenómeno de la autoconciencia que había tratado a fondo en su libro homónimo, pero quizá no desea entretenerse aquí con un concepto filosófico tan fuerte ni contender de frente con teorías analíticas como la de John Perry (1979), que se publicaron casi a la vez que Autoconciencia, sobre la referencia del pronombre personal "yo" y los demostrativos (véase Tugendhat 2005). Por ende, a él le viene bien ese giro para presentar después la mística como una forma de auto-distanciamiento que puede llevar a cabo quien dice "yo".

La argumentación de Egocentricidad no discurre de forma lineal, sino más bien por acumulación de fuerzas o supuestos conexos. El primero es que el lenguaje proposicional, mediante el uso de términos singulares, hace posible que sus usuarios hagan referencia a objetos y situaciones independientes de la situación perceptiva actual. Tal es, a mi juicio, el argumento principal de Vorlesungen zur Einführung (Bonet 1992, pp. 317-356 y 392-497). Para demostrarlo, Tugendhat se fajó allí con las teorías analíticas de las descripciones de Russell, Strawson y Donnellan. Pocas veces se ha reparado en que la compleja teoría resultante es un intento admirable de traducir a categorías comprensibles, fundadas analíticamente, cuestiones clave de la analítica heideggeriana de la existencia (Dasein) como ser-en-el-mundo, particularmente de las interremisiones de los términos deícticos mencionados en el \$26 de Sery tiempo (yo, tú, él, aquí, ahí...). Quien dice “yo" competentemente debe saber usar las expresiones deícticas u ocasionales, cuya referencia cambia con los

15 Tugendhat 1979, pp. 179 s. / 1993 a, pp. 141 s. 
contextos de uso, comenzando con los pronombres personales, los demostrativos (esto, aquello) o los adverbios de lugar y tiempo (ahora, antes, después), que también son términos singulares, como ya explicó Frege. Ha de saber asimismo algo que Descartes olvidó: que dichas expresiones componen series, como acabamos de recordar, las cuales presuponen una comunidad de hablantes que intercambian la palabra, así como su lugar en un espacio que, quien dice "yo", percibe siempre en relación consigo mismo. Por último, si, además de hacer referencia a objetos y situaciones — los "particulares" de Strawson_- desea identificarlos concluyentemente ante la audiencia, añade Tugendhat que ha de situarlos, mediante descripciones localizantes relativas a días y lugares, en un sistema de referencias objetivo: un mundo. Así, dominando el plexo de inter-remisiones que componen los distintos tipos de términos singulares (denotativos de un particular) que acabamos de mencionar,

Con el lenguaje predicativo aparecen a la vez la conciencia de otros objetos y la conciencia de sí mismo como un objeto entre otros, entretejidas con la conciencia de un mundo objetivo en el que tanto yo como las demás personas ocupamos un lugar. (2003, pp. 28 s. / 2004, p. 32)

En este contexto, el problema mayor de este planteamiento, que es el de Vorlesungen zur Einführung, en nuestro contexto es que así no alcanza Tugendhat el plano de la autoconciencia práctica ${ }^{16}$ en el que hundirá sus raíces la espiritualidad ${ }^{17}$, pues se trata únicamente de conciencia de objetos del mundo espacio-temporal ${ }^{18}$.

¿Qué se entiende por egocentricidad? En primer lugar, podemos hablar de una sensibilidad "egocéntrica" o egocentricidad rudimentaria ligada al fenómeno de la conciencia que también se da en muchos animales no humanos; cada organismo es fácticamente el centro de sus propias experiencias. A continuación está la autoconciencia epistémica inmediata por la que quien dice yo sabe que los

16 Desde el punto de vista de la filosofía del lenguaje, pueden discutirse también alguno de los pasos que da Tugendhat. De modo particular, el concepto de especificación de la lección 22, 1976 , pp. 407 ss., la idea de que el objeto identificado es uno entre todos los que se encuentran en ese mundo. Ver Bonet 1992, pp. 434 ss.

17 El propio Tugendhat lo reconoce en la primera frase del capítulo II, 2003, p. 30 / 2004, p. 35. 18 También Schleiermacher (2013, p. 45) pone en relación la piedad, o autoconciencia religiosa, con el mundo: "nuestra autoconciencia, como una conciencia de nuestra existencia en el mundo o de nuestra co-existencia con el mundo, es una serie en la que el sentimiento de libertad y el sentimiento de dependencia están divididos”. Ninguno de estos dos sentimientos aparece al identificar los objetos en un mundo espacio-temporal. 
sentimientos y pensamientos que tiene son "suyos", le pertenecen". Junto a ello, en opinión de Tugendhat, está implícito en la teoría de la referencia de los términos singulares que acabamos de bosquejar que cada ser consciente que dice "yo" se vea y perciba a sí mismo como el centro de un mundo que ahora se descubre como cohabitado por otros "centros" con idéntica pretensión. El siguiente escalón, acaso un tanto precipitado en la explicación de Tugendhat, es que quien dice "yo" se da a sí mismo una importancia desmedida. Todo lo cual anda envuelto en, o acompañado de, una implicación afectiva egocéntrica de deseos, temores y preocupaciones que nos provoca mucho sufrimiento ${ }^{20}$.

Hasta aquí el primer supuesto de Egocentricidad, acaso el más complejo. El siguiente es como un ramillete de ideas que se entretejen para hacer plausible por qué quien dice "yo" puede plantearse planes de futuro. En efecto, con el lenguaje proposicional aparece también en los seres humanos (a) la conciencia del tiempo, en particular, la posibilidad de referirse a un futuro que no se puede percibir ahora ni depende de la situación perceptiva actual ${ }^{21}$. Y emerge igualmente (b) la conciencia de lo bueno $(2004$, pp. 27, 40). ¿Cómo justifica Tugendhat este paso? Apelando al libro I de la Política de Aristóteles, cuando al principio señala que el hombre es más sociable que las abejas, los insectos o el ganado porque la palabra (logos) le permite expresar y comunicarse sobre lo bueno y lo malo, lo justo y lo injusto, como algo distinto de lo placentero o lo doloroso. (c) Con la racionalidad instrumental y los dos elementos recién mencionados, nos encontramos con la reflexión, eventualmente comparativa, sobre fines a alcanzar, independientes de la situación y representados como buenos, y sobre los medios que conducen a su consecución. Los seres humanos se proponen fines, persiguen objetivos y pueden también anticipar tanto el éxito de esos objetivos como la posibilidad de que ocurran males y fracasos ${ }^{22}$.

19 Por mucho que yo sufra viéndola, el dolor de dientes de mi hija le pertenece solo a ella. A mí se me parte el corazón, pero no me duelen los dientes.

20 Tugendhat, 2003, pp. 8 s., 29-31, 39 / 2004, pp. 11, 33, 35 s., 45 s.

21 "Es esencial para los hombres preocuparse [sorgen] por su futuro. Esta característica se funda en el lenguaje y en la conciencia del tiempo, que son propias de esta especie" (Tugendhat 2007b, p. 144 / 2007a, p. 163).

22 Corrigiendo a Aristóteles, Tugendhat insiste en que, de hecho, los hombres tenemos una pluralidad de fines que no son medio para ninguna otra cosa, como las actividades que realizamos por ellas mismas, como "fines en sí mismos" (Selbstžweck), como jugar o pasear, o las personas o seres por cuya existencia y bienestar nos preocupamos como "fin último" (Endzweck), como ocurre con nuestra propia existencia, la de otros o la de entidades como una obra de arte o un Estado (Tugendhat 2003, p. 36 / 2004, p. 42). 
El tercer supuesto está implícito en el párrafo anterior, pero conviene estudiarlo por separado. Es la posibilidad de preguntarse y conducirse, en un sentido práctico y emocional o volitivo, respecto de la propia vida en su totalidad. Es la cuestión del sentido de la vida, de cómo queremos ser o vivir, no en relación con tal o cual fin o plan determinado, sino con el conjunto de nuestra vida. Así formulada, en forma interrogativa y no asertiva, acaso sea esta la cuestión central de la filosofía toda de Tugendhat. Tras escribir el planteamiento la primera vez que impartió un curso de ética, en 1973, lo incluyó en la singular lección 7 de Vorlesungen zur Einführung, reproduciéndolo luego en los otros cuatro libros suyos más $\operatorname{conocidos}^{23}$. No es posible desentrañar el sentido de la interrogación sin hacer referencia directa al Heidegger de Sery tiempo, por más que el autor de Egocentricidad a veces parezca olvidarlo. Heidegger afronta la existencia, Dasein, como un modo de ser distinto del de los entes que pueden ser observados y analizados desde fuera, en tercera persona. La existencia, por el contrario, es en cada caso la mía; se vive y se sufre en primerísima persona, y de ahí el concepto de egocentricidad. No se observa o analiza, sino que se "hace" (o se deja de hacer) algo con ella. De ahí el giro alemán Sich-zu-sich-Verhalten, el conducirse respecto de sí mismo ${ }^{24}$, con el que el autor rotula los capítulos principales de Autoconciencia_-dedicados a Heideggery primera sección de Egocentricidad (Sich-Verhalten zu sich). Religión y mística serán formas de conducirme respecto de mí mismo.

Teniendo en cuenta la filosofía del lenguaje de Tugendhat, la objeción está servida: ¿cómo hace referencia (en el sentido semántico del término) alguien a su vida? La expresión "mi vida en su totalidad", ¿es un término singular? En tal caso, ¿cómo se identifica su referente? Y si no es un término singular, ¿qué es o cómo habría que manejarla desde un punto de vista semántico? La respuesta de Heidegger no apunta hacia el lenguaje, al menos directamente: el fenómeno glo-

${ }^{23}$ Bonet 2013, pp. 92 nota y 303 ss. Por aducir un ejemplo desconocido, su comentario a C. Taylor en Tugendhat 1992, pp. 441-452.

${ }^{24}$ En contextos académicos el Verbalten alemán se traduce al inglés como behaviour, que, a su vez, se vierte al castellano con dos variantes: comportamiento y conducta. Los traductores hispanos de Tugendhat, probablemente con su aprobación (no siempre certera), suelen eligir la primera y hablan de un "comportarse (o comportamiento) consigo mismo". Solo que "en español no existe tal cosa; uno se "comporta", o no, únicamente con otros (nunca "consigo mismo"), a menudo con una connotación moral ("se comportó como un auténtico amigo") de la que carece la expresión heideggeriana”. (Bonet 2013, p. 264 nota). Adoptar la segunda opción en su forma verbal, conducirse, no tiene esos inconvenientes y resulta casi tan flexible como la fórmula alemana. 
bal de nuestra vida asoma o se hace presente en los estados o temples de ánimo (Stimmumg), que no tienen un objeto intencional directo, sino que tratan de cómo "le va" (la vida en general) a uno o una ${ }^{25}$, y en particular en la angustia ante la muerte (en la próxima sección).

Tres son las formas en que Tugendhat ha tratado de arraigar en el lenguaje esta autoconciencia práctica. Primero, insistiendo en el carácter proposicional de los estados de ánimo, siguiendo en esto a Kenny (1963). Segundo, definiendo un tipo de oraciones prácticas, las oraciones de intención, que declaran en primera persona planes de futuro — como "iré al cine este sábado"—, mas no en la forma de un pronóstico, sino como correlato a eventuales consejos en forma imperativa (“iVe al cine este sábado!" - "De acuerdo, iré”). Tercero, y más importante en el argumento de Egocentricidad, mediante una clase de enunciados de intención que no solo presentan posibilidades futuras en primera persona, como "puedo ir al cine este sábado" o "puedo cambiar de trabajo", sino el deseo del agente que dice "yo" de "activarse" o "ponerse en marcha", de esforzarse por llevar a cabo cierta acción (o actividad) que, al menos en parte, depende de él. Por supuesto que tales exhortaciones pueden dirigirse también en segunda persona: "ánimo, puedes hacerlo, depende de ti”. Lo decisivo, en el marco de este libro, más que la cuestión del libre albedrío, con la que Tugendhat seguirá debatiéndose (y retractándose) en Antropología, es que, cualquiera que sea el grado de libertad que atribuyamos al agente $^{26}$, este se ve a sí mismo como imputable, es decir, como responsable de su acción. Y eso significa, ni más ni menos, que quien dice "yo" y se piensa como imputable puede sentirse culpable y avergonzarse por lo que hace mal o deja de hacer bien ${ }^{27}$. Y hay que pensar que esto no solo se puede aplicar a acciones concretas, sino también, al conjunto de nuestra vida. Tugendhat proyecta de este modo al tema de la autoconciencia existencial la teoría de los sentimientos morales que elaboró para su fundamentación de la moral ${ }^{28}$. Y porque la sombra de Heidegger es alargada, resulta que en ambas forma de conciencia, la existencial y la moral, el plano afectivo resulta decisivo (Henrich, 2006). La consecuencia es que quienes

\footnotetext{
25 Lo diré así esta sola vez.

26 "El grado que puede alcanzar el esfuerzo y la concentración [del agente] está causalmente determinado, pero sólo yo puedo averiguar dónde se encuentra el límite... dicho límite no consiste en una magnitud fija; se trata de un espacio en que oscila el que se esfuerza y, desde luego, solamente cuando se esfuerza" (2004, p. 60 s. / 2003, p. 53).

27 2003, pp. 62-64 y 74 ss. / 2004, pp. 70-72 y 83 ss.

28 Tugendhat 1990 y 1993b, lección 3; Bonet 2013, pp. 161-169.
} 
dicen "yo", porque depende de ellos hacerlo mejor, tienen una causa de pena o sufrimiento adicional, que se une a los dolores corporales, las pérdidas y el fracaso de nuestros planes de futuro (2003, p. 63 / 2004, p. 71). El asunto que aquí se ventila es la contingencia de la vida humana, que proseguimos en la siguiente sección.

Antes, sin embargo, aún hay que mencionar un cuarto supuesto o hilo argumental que el autor despliega específicamente en Egocentricidad: la tendencia de quien dice "yo" a atribuirse una importancia desmedida. Quien dice "yo" necesita sentirse reconocido ${ }^{29}$, en primer lugar, por su propia existencia, de manera gratuita. Sin ello no podría ni sentirse digno de ser amado ni tampoco valorar como importante cosa alguna, empezando por la propia vida (Tugendhat 1993b, lecciones 14 y 15). Necesita también, en segundo lugar, sentirse reconocido como bueno por lo que hace, por el modo de desempeñar actividades que el propio agente considera importantes. Es lo que Tugendhat llama el bien adverbial. No se olvide que nuestra vida consiste prácticamente en lo que hacemos y dejamos de hacer. Nos hallamos, pues, en primer lugar, con la necesidad de que nuestra propia existencia y bienestar sean considerados por otros como intrínsecamente valiosos. Y, en segundo lugar, por la necesidad voraz, que dura toda la vida, de confirmar el propio valor siendo reconocidos por nuestro buen hacer ${ }^{30}$. Con lo cual a menudo se confabula, para darnos importancia a nosotros mismos, la creencia de que nuestras acciones y actitudes influyen en la realidad, son importantes para lo que sucede o puede suceder en el mundo.

Se trata, en todo caso, de componentes estables de nuestra egocentricidad que los otros animales no conocen. Para vivir más felices, los humanos necesitan darse, entregarse a algo distinto de sí mismos, trascenderse y vivir su egocentricidad sin egoísmo. Así que el altruismo o la generosidad representan una forma de darse menos importancia a sí mismo, algo que la mística llevará a sus últimas consecuencias ${ }^{31}$.

\footnotetext{
29 Tugendhat se apoya en este punto en T. Todorov (1995). Al mismo tiempo, proyecta sobre el cap. 2 de Egocentricidad sus disquisiciones sobre la motivación de la moral de las Lecciones de ética (la 14 y la 15), a propósito de E. Fromm y A. Smith, que empezaron a decantarse en sus Retractaciones a las Tres lecciones de ética de Probleme der Ethik (que comenta con detalle Bonete 1990), con una sugerente fusión de horizontes kantianos, heideggerianos y de Fromm/ Smith que nuestro autor simplificaría notablemente en las Lecciones de ética.

30 2003, pp. 44 s. / 2004, pp. 50 s.

31 Tugendhat 2003, pp. 86 s. / 2004, pp. 96 s. He hecho referencia deliberada a lo que Tugendhat llamó "trascendencia inmanente" en uno de los trabajos fundacionales del ciclo antropológico, "Nietzsche y la antropología filosófica: el problema de la trascendencia inmanente": 2002, pp. 215 ss. (redacción original) / 2007a, pp. 13 ss. (versión alemana ampliada).
} 


\section{CONTINGENCIA Y ESPIRITUALIDAD}

Decía la antropóloga de la religión Mary Douglas, a propósito de la primera edición de la Enciclopedia británica (1773), que, cuando esta dividía la entrada "Magia" en las categorías de idolatría, religión sacerdotal y filosofía de la religión, separaba "lo que en el campo el antropólogo encuentra como una única experiencia"; y que "la tradición escéptica se siente cómoda haciendo divisiones entre las diversas partes de la religión, identificando una parte admirable y otra despreciable" (Douglas 1998, p. 199). Algo así podría decirse del modo enteramente personal (o "first personal", como veremos) en que Tugendhat contrapone religión y mística. En rigor, él analiza poco la religión, en el sentido que suele tener el término en la antropología cultural, en referencia a los ritos y simbolismos de una comunidad. ¿De qué habla, pues, nuestro filósofo? En realidad de una cierta forma de autoconciencia que Schleiermacher definía como "la conciencia de ser absolutamente dependiente o, lo que es lo mismo, de hallarse en relación con Dios” (2013, p. 42).

En Raíces, artículo de la serie fundacional, la mística es para Tugendhat una forma de radicalización y profundización de lo religioso. En cambio, en Egocentricidad, se tensa la diferencia entre ambas experiencias indicando que arraigan de forma muy distinta, incluso opuesta, en la contingencia. A pesar de ello, en dicho libro y en los artículos de Antropología, Tugendhat admite que hace falta algún concepto general que incluya religión y mística, o alguna forma de conciencia protorreligiosa o protomística que él formula con la ayuda de Rudof Otto (2001): la clave está en la experiencia de la pequeñez humana ante lo numinoso o estremecedor de la naturaleza, lo 'incomparablemente grande', frente a lo cual "uno se experimenta a sí mismo como pequeño" y ante lo cual se inclina ${ }^{32}$. Más tarde, en Spiritualität, Tugendhat asocia dicha interpretación al sentimiento oceánico de lo ilimitado que Freud situaba como fuente de la religiosidad en El malestar de la cultura. Y además, encuentra un término, el de espiritualidad, que seguramente responde a lo que desde el principio intentaba decir. Pero este no es exactamente un concepto común para lo místico y lo religioso, sino que define una forma de autoconciencia o autorrelación práctica que arraiga en la conciencia del futuro y define una línea de separación con la conciencia de los otros animales. Estos tienen conciencia de males y peligros concretos, como los dolores corporales, pero no los anticipan y para ellos "el hecho de estar limitados no significa nada" (2004, p. 110 / 2003, p. 98).

32 Tugendhat 2003, p. 119 / 2004, p. 134; 2007a, p. 178 / 2007b, p. 159. 
En paralelo a nuestro planteamiento de la sección precedente, la autoconciencia práctica humana da lugar a un tipo de reflexión diferencial en el que cabe distinguir dos niveles ${ }^{33}$ : la ordinaria, o de primer nivel, versa sobre los medios para alcanzar fines, o para evitar peligros, y sobre los fines alternativos que podemos comparar entre sí. Pero hay un segundo nivel de reflexión, propiamente espiritual, en el que nuestra existencia se ve confrontada prácticamente con los diversos lados de la contingencia, entendida esta como un término general denotativo de la finitud existencial humana (Endlichkeit). Algunos de esos lados los hemos mencionado, pero hay más.

Tenemos planes e intenciones de futuro cuya realización no depende solo de nuestro empeño, sino también de factores que no podemos controlar o instrumentalizar. Así es que quedamos expuestos al problema del azar o de la "mala suerte" (2002, pp. 215 ss.). Algo similar ocurre en relación con la vulnerabilidad a las desgracias y las pérdidas, las propias y las cercanas. En este mismo nivel podríamos situar nuestra dependencia de altibajos emocionales o afectivos (2003, p. 95 / 2004, p. 107). El caso es que cada uno de nosotros se halla fácticamente expuesto a la frustración, los límites, el dolor y las pérdidas.

Pero es que, además, la conciencia del tiempo implica también la de la caducidad o transitoriedad de las cosas naturales y humanas. Implica asimismo el temor al vacío del tiempo, al aburrimiento; y, por supuesto, la angustia ante la muerte como pérdida incomparable de la vida, la finitud extrema. Tugendhat se esfuerza, en distintos trabajos, en precisar el alcance de dicha angustia, mas lo que aquí nos importa es que la perspectiva de la muerte nos lleva a confrontarnos con nuestra vida en su conjunto y a preguntar por su sentido. En dicha confrontación, mi vida se despega, por así decir, de la multitud de asuntos y preocupaciones en la que anda dispersa y aparece, en el plano afectivo, como algo unitario. No solo nos medimos con el éxito o fracaso de objetivos particulares, sino que podemos plantearnos la pregunta que llamé existencial por el conjunto y el motivo unitario de nuestra vida o el sentido de la misma.

Tugendhat afirma más de una vez que ni Aristóteles ni, en general, el pensamiento griego llegaron a convertir la reflexión espiritual en un problema filosófico merecedor de atención continuada; algo que sí hicieron las culturas judía, chinas

${ }^{33}$ En Raíces menciona Tugendhat tres niveles de deseo, a partir de la distinción de Harry Frankfurt entre deseos de primer y de segundo grado. La pregunta práctica por el cómo global de nuestra vida representaría el tercer nivel. Pero dicha estratificación desaparece en los escritos posteriores. 
e indias. Grecia se queda en un plano "pre-espiritual" que nuestro autor reputa insuficiente ${ }^{34}$. ¿Podemos hablar de un existencialismo tugendhatiano? En mi opinión, $\mathrm{si}^{35}$, a condición de que se sobreentiendan algunas observaciones. Pues Tugendhat no se recrea en la tradición existencialista, sino que retoma con libertad aspectos antropológicos parciales de Ser y tiempo, el libro que tanto le influenció, cuyos temas, llegado el momento, confronta con la propia vida. Tampoco concibe la contingencia o la temática existencial como el único problema filosófico importante, en lo cual viene a coincidir con Heidegger. Se separa de él, sin embargo - y esta vez sin muchos aspavientos-, en algo que, en realidad, fue su caballo de batalla con el filósofo de la Selva Negra desde Die Wahrbeitsbegriff: que se trata de una reflexión, potencialmente deliberativa, que no rehúye de entrada la dimensión de la justificación ${ }^{36}$. La pregunta práctica fundamental (grundsätzlich) sobre mi propia vida abre una reflexión referida a cómo quiero vivir que da un paso atrás ante la dispersión en la cotidiana multitud de asuntos prácticos y medita sobre uno mismo y el sentido de la propia vida. Una pregunta que a veces nos abruma y nos empuja a "perdernos" en los asuntos concretos. En todo caso, es en ese retraimiento que la pregunta misma provoca, en esa unificación de nuestra propia vida, donde pueden emerger la religión y la mística, en relación con una problemática existencial común a otros seres humanos, pero que cada uno aborda - $\mathrm{O}$ no- $-\mathrm{y}$ resuelve a su manera, sin que sea exigible una respuesta común para todos.

En suma, la espiritualidad es una forma de reflexión que consiste en habérnoslas con el conjunto de nuestra vida, considerada de forma unitaria, sabiendo que terminará y cuán expuesta está, de hecho, a las frustraciones y el sufrimiento. Es una posibilidad de la razón natural que, sin embargo, no se produce de forma espontánea.

\section{RELIGIÓN Y HONESTO ATEÍSMO}

Casi todo lo que se escribe actualmente en las áreas de fenomenología e historia de la religión obedece a la perspectiva de la tercera persona. Puesto que yo asumo la perspectiva de la primera persona, ya al definir la religión y la mística debo procurar que las definiciones impliquen alternativas prácticas con sentido para nosotros hoy en día (Tugendhat 2004, p. 129 / 2003, p. 115).

\footnotetext{
34 En este punto, la posición de Spiritualität (2012, pp. 162-165) es distinta de la de Raíces, donde Tugendhat intentaba aproximar la mística oriental a las posiciones de Heráclito y Parménides.

35 Quizá sea en Spiritualität y sobre todo en el capítulo 5 de Egocentricidad donde mejor se muestra. 36 Tugendhat 1967; 1969; 1979 / 1993a; Bonet 2017. No sabría decir, empero, de qué modo opera la justificación en el tipo de reflexión espiritual que Tugendhat patrocina.
} 
Así que Tugendhat plantea su teorización de la religión y la mística como una “filosofía en primera persona". ¿Qué quiere decir con ello? Distinguir y coordinar las perspectivas de la primera y la tercera persona, fue una de las claves de la interpretación de Wittgenstein y Heidegger —en cada caso de una forma-, en relación con la autoconciencia epistémica y la práctica, respectivamente, en el libro de 1979. Pero es en relación con la ética y midiéndose con Gadamer como articula la complementariedad de ambas perspectivas filosóficas: en tercera persona, desde la perspectiva del observador, podemos describir, por ejemplo, las convicciones morales de una sociedad y las causas de las mismas. Mas solo es posible tener convicciones morales en primera (o segunda) persona, cuando uno las considera correctas y defendibles con razones, sin relativizar su validez atendiendo a factores objetivos (Bonet 2013, pp. 104-108). Estamos, pues, ante una distinción entre las perspectivas del observador y el participante, la de las causas y la de las razones, que se proyecta igualmente en las disquisiciones antropológicas de Tugendhat sobre el libre albedrío (2007a, pp. 57-84 / 2007b, pp. 39-64). Aplicada a la religión y la mística, filosofar en primera persona es preguntar qué puede significar el fenómeno para nosotros hoy en día, plantearse si tenemos o no razones para considerar válida esa modalidad de autoconciencia práctica en primera persona (2003, pp. 114-115 / 2004, p. 129 s.). Y es que solo desde la perspectiva de la primera persona puede presentarse la mística como una opción de vida válida (Wenning 2017, p. 562). Pero ello presupone, añade Tugendhat, una investigación lo más amplia posible desde la perspectiva del observador, en la medida en que ambas perspectivas "surgen de una estructura semántico-gramatical unitaria"37.

Así las cosas, desde esa perspectiva de primera persona, para Tugendhat, el criterio de demarcación entre religión y mística está en afirmar, o no, la existencia de seres espirituales. Dicho concepto, no solo deja en segundo plano los aspectos comunitarios y rituales de la religión, que suelen predominar en la antropología cultural, sino que comporta cierta confusión conceptual, por cuanto el autor se ve obligado a admitir, por un lado, que en figuras como Jesús de Nazaret o el maestro Eckhart nos encontraríamos a místicos en formato religioso, mientras que, en el otro lado, Tugendhat tacha de inconsecuente al budismo zen japonés por hacer

\footnotetext{
37 La afirmación (2004, p. 188 / 2003, p. 169) parece referirse a la simetría veritativa entre "me duelen las muelas" y "le duelen las muelas" analizada por Tugendhat en la $6^{a}$ lección de Autoconciencia. Pero es harto discutible que pueda aplicarse sin más a las perspectivas del observador y el participante en los fenómenos religiosos y místicos, donde las dos perspectivas no tienen por qué intercambiarse.
} 
reverencias ante el vacío, como si se tratara de una persona (2007a, pp. 197 s. / 2007b, p. 181), por lo que afirma que hay místicas religiosas y otras, supuestamente más consecuentes, que no lo son. En todo caso, ello denota que, para el autor, desde la perspectiva de la primera persona, la cuestión del ateísmo es crucial. Su tesis central es que, "hoy en día", el tipo de ateísmo que él profesa es la única posición "intelectualmente honesta".

¿Qué se entiende por honestidad intelectual? Es este uno de esos temas filosóficos específicamente tugendhatianos que la tradición filosófica apenas ha considerado, por más que cuente con precedentes tan ilustres como Sócrates y Nietzsche, curiosos compañeros en esta singladura. Tugendhat no se refiere a una virtud moral, sino a una especie de voluntad de verdad, entendida, en primer lugar, como el buen desempeño de la propia actividad intelectual (y aquí entraría también el arte, aunque no se guíe por el concepto de verdad), frente al aplauso fácil o al dejarse caer en lo que "se" espera de nosotros; y, en segundo lugar, o de modo más específico, entendida como la disposición a ganar claridad (o verdad) sobre nosotros mismos o sobre la propia vida, hasta el punto de estar dispuesto a abandonar las propias opiniones cuando se revelan injustificadas, aunque ello no resulte agradable o satisfactorio. Este interés por la verdad, en tensión por el interés en la no-verdad (Unwahrheit), definió en gran medida el proyecto de Die Wabrheitsbegriff (1967, pp. 1-7, 192 s. y 316 ss.) y la interpretación de Tugendhat de la idea husserliana de autorresponsabilidad. Está supuesto también en toda la fase analítica de nuestro autor y reaparece con fuerza cuando este autor se enfrenta, en sus escritos pacifistas $\left(1988^{2}\right)$, a la pereza de la razón y el interés social en el autoengaño colectivo de negarse como real el peligro nuclear. Sin embargo, en este ciclo antropológico la cuestión adquiere singular importancia, toda vez que Tugendhat se ha ido deslizando en una actitud postmetafísica ${ }^{38}$ ante la verdad, cuyo atractivo ya no le parece evidente o que se pueda dar por descontado. Entonces se pregunta Tugendhat por los motivos de la honestidad intelectual sin llegar a conclusiones suficientemente claras ${ }^{39}$. En cualquier caso, sean cuales sean los motivos, Tugendhat afirma de forma reiterada, no poco sorprendente, que el ateísmo es como la prueba decisiva de la honestidad intelectual, su exponente más inequívoco. ¿Por qué?

38 A pesar de que el propio Tugendhat rechazaba este término briosamente, conviene también en él Wenning, 2017, p. 555.

39 Lo he tratado con más detalle en (Bonet 2013, pp. 281-288). 
Su argumento consiste en una modificación del de Freud, que considera la creencia religiosa como un residuo de la niñez y la mera proyección ilusoria de un deseo (Wunsch). Tugendhat rechaza que la creencia religiosa sea infantil por definición, precisamente por haber localizado en la contingencia la raíz antropológica de lo numinoso — común a religión y mística — que da lugar al deseo o la necesidad de que existan seres sobrenaturales que transformen el mundo, para aliviar o evitar nuestras frustraciones y la mayor de ellas, que es la muerte. El problema está en que tales seres existirían fuera del espacio y del tiempo ${ }^{40}$. Entonces, no hay, y no puede haber — sostiene Tugendhat_- ninguna evidencia de su existencia independiente del deseo mismo. Como, además, tenemos una concepción científica del mundo, entonces - prosigue — el deseo se convierte en una razón contraria a la existencia de lo deseado, que no es más que un espejismo. La afirmación de que existe Dios o dioses sería alucinatoria, si no fuera porque se refiere a una esfera sobre-natural ${ }^{41}$.

Tal es, según el autor, la única posición intelectual sostenible respecto de la religión. Pero existen otras tres alternativas que debemos comentar someramente. Una es el ateísmo que podemos llamar indoloro, frecuentemente ideológico, de quienes, como Nietzsche o Freud, consideran que el hombre puede instalarse cómodamente en la finitud, negando el problema de la contingencia que hemos presentado como la raíz antropológica de lo religioso y considerando el ateísmo como una liberación. En su favor, además de lo dicho, milita el hecho de que "en general la vida es hoy más fácil” (2002, p. 221) y que, por consiguiente, cuesta menos relegar las frustraciones de la vida a los rincones de la vida social, como las clínicas o los manicomios. Como dicha actitud niega el carácter problemático de la finitud, no deja más salida, ante las frustraciones de la vida, que la de "apretar los dientes", la cual,

es tan poco satisfactoria porque no permitiría una actitud uniforme de la voluntad del ser humano dentro de las visicitudes de la vida. Confrontada con la muerte, una persona quiere tener una concepción coherente de la vida. Me parece problemático, aunque posible vivir al día, hoy gozando, mañana desesperado, y quedando a merced de mis emociones y sentimientos pasajeros. (2002, p. 222)

\footnotetext{
40 Procede recordar ahora que, a raíz de Heidegger, el concepto de existencia en el espacio y el tiempo cobró para el Tugendhat analítico la máxima importancia (Tugendhat y Wolf 1983, pp. 197-200; y Tugendhat 1992, pp. 67-89), por más que no lograra articularlo completamente, como se comprueba en la $2^{\mathrm{a}}$ parte de Vorlesungen zur Einführung.

41 Puede leerse el argumento en Tugendhat 2002, 220-222; 2003, pp. 123 s./ 2004, p. 139; 2007a, pp. 191-193 / 2007b, pp. 173 s.
} 
Las otras dos posiciones posibles son el agnosticismo y la creencia religiosa. La primera intentaría situarse en un imposible lugar intermedio entre la creencia y la increencia, presuntamente respetuosa con todos, por haber malentendido — acusa Tugendhat — que, dada la inverificabilidad de la existencia de seres espirituales, el solo deseo de creer, no respaldado por evidencia alguna, no puede contar a favor de la creencia ni de la suspensión del juicio, sino solo en contra de ella. En cuanto a la creencia, Tugendhat la tacha, al comienzo de su ciclo antropológico, de abiertamente deshonesta; más adelante suaviza ligeramente su dictamen, al considerarla, desde el punto de vista intelectual, como "ingenua o deshonesta" El ateísmo honesto que propugna Tugendhat comporta asumir una contradicción entre el deseo de creer y la imposibilidad de satisfacerlo honestamente.

La filosofía de la religión de Tugendhat no se agota, empero, en la defensa del ateísmo. También hace referencia a los motivos de la conciencia religiosa y, sobre todo, al ramillete de actos espirituales que la constituyen. En cuanto a lo primero, junto a la experiencia de lo numinoso y el deseo de personalización, hay que mencionar otras fuentes de la religiosidad, como el consabido motivo pragmático de buscar el apoyo en un ser superior que supuestamente puede incidir causalmente en el mundo, o la creencia, no universal pero sí frecuente, de que la incomparable bondad divina representa un anclaje sólido para la moral y el Derecho, así como un impulso para el altruismo.

Entrando ya en la descripción (fenomenológica, en realidad) de los actos espirituales típicos de la religión, Tugendhat analiza en particular el fenómeno de la oración, distinguiendo diversas formas de la misma ${ }^{43}$. Comencemos con la oración de petición o súplica, que se refiere al curso futuro de los acontecimientos. En ella cabe distinguir tres formas. Una es la forma mágica, que se dirige a los poderes divinos en tercera persona, como si fueran objetos naturales que se pueden manipular. Otra es la postura religiosa por excelencia, en la que el creyente suplica, ya en segunda persona, la asistencia de un ser personal. Pero hay también una tercera forma de petición, que Tugendhat considera mística y que siempre ejemplifica con las oraciones de Jesús, en el huerto de Getsemaní ("no se haga mi voluntad, sino la tuya”) y en el Padrenuestro ("hágase tu voluntad...”), en las que el creyente

42 2002, p. 222; 2007a, p. 193 / 2007b, p. 176

43 Si aplicamos la distinción entre las perspectivas de la primera y la tercera persona, diría que el análisis que sigue lo lleva a cabo el autor — sin decirlo — desde la perspectiva de la tercera, mientras que cuando evalúa los costes que comporta el ateísmo, se desliza ya a la posición de la primera persona, que sí menciona también en este contexto. 
renuncia a manipular el poder divino y relativiza su propia voluntad, aceptando el curso de la realidad, o la voluntad divina. Así, lo que inicialmente parecía malo, en función de los propios deseos, se transforma en algo bueno, al margen de ellos. Por venir de Dios, las frustraciones son integradas como algo positivo y la vida en su totalidad adquiere sentido (2002, pp. 219 s.).

En Über Religion, se detiene Tugendhat en la oración de acción de gracias. La historia de las culturas constata cuán frecuentemente han sentido los hombres la necesidad de dirigirse con gratitud a seres divinos, tanto en relación con el pasado y con el cumplimiento de metas ordinarias, como para dar gracias por la propia existencia y la de seres queridos. ¿'Tiene sentido esa acción de gracias, cuando se niega la existencia de los dioses? Tugendhat piensa que el agradecimiento no puede ser anónimo o impersonal, no dirigido a nadie en particular. Distingue entre la sorpresa (Verwunderung) y el dar gracias, y pone como ejemplo las emociones que puede sentir una madre ante su hijo pequeño: la sensación de sorpresa o asombro $^{44}$ puede no referirse a nadie en particular; en cambio, la dación de gracias por su existencia solo tiene sentido si se dirige a un destinatario personal, que no puede ser el propio niño, sino un ente al que también se le puedan pedir cosas. Concluye, pues, que si no hay seres divinos, no se puede rezar, sin dejar de reconocer "honestamente" que, con ello, los seres humanos perdemos algo importante.

Además de la petición, el agradecimiento o la alabanza, hay otra forma de relación con seres poderosos ${ }^{45}$ a la que nuestro autor dedica singular atención en las últimas páginas de Über Religion ${ }^{46}$, la de sentirse responsable ante ellos por la propia vida, actitud que en la mística oriental desempeña un papel menor que en occidente. Es este un fenómeno que Tugendhat estudió en Der Wabrheitsbegriff en relación con la Selbstverantwortlichkeit husserliana, fuente de su concepto de honestidad intelectual. Téngase en cuenta el papel central que tienen en la filosofía moral de nuestro autor los juicios morales negativos, los reproches y el sentimiento de culpa (Tugendhat 1990; Bonet 2017), todos los cuales carecerían de sentido si su destinatario no fuera responsable de sus actos o imputable por ellos. Claro está

44 Uno de los epígrafes finales de Egocentricidad trata del "asombro" (Staunen) por la existencia del mundo, en relación con la Conferencia sobre ética de Wittgenstein. El texto español de Über Religion habla también de asombro en relación con el ejemplo de la madre; pero el texto alemán, más cuidado, emplea preferentemente en este caso el término Verwunderung.

45 2003, p. 122 / 2004, p. 137

46 Vuelve sobre ello en relación con el libre albedrío, sobre todo en la postdata de 2006 (2007a, pp. 74-84 / 2007b, pp. 52-63). 
que tiene pleno sentido responder de acciones y omisiones ante los otros miembros de la comunidad moral. Pero, ¿existe algo así como una responsabilidad por la propia vida en su conjunto - el aspecto que resulta decisivo en la autoconciencia práctica—? Una comunidad moral moderna no puede inmiscuirse hasta ese punto. Sin duda, tal responsabilidad tendría sentido en relación con Dios, como plantea Kierkegaard, entendiendo que sin ella se esfumaría la seriedad de la vida, tal y como decía Macbeth. Pero, ¿no puede tomarse uno su propia vida en serio si no es en relación con un ser superior? La $1^{\mathrm{a}}$ edición de Antropología se cierra con esa pregunta. Tugendhat, quien años atrás defendiera tentativamente una moral de la seriedad ${ }^{47}$, no puede responder negativamente a la pregunta. Pero se ha quedado ya sin fundamentos para elaborar una respuesta afirmativa.

Hay otros actos espirituales ${ }^{48}$ en los que el ser humano, conduciéndose respecto de un ser superior, se relaciona con el conjunto de su propia vida; así, la alabanza, la sumisión, la humildad o la conciencia de pecado. Alguno de ellos, sobre todo la humildad, Tugendhat lo remite a la mística.

\section{MísticAS ORIENTALES Y PAZ INTERIOR}

$Y$ es que es en la mística donde los actos espirituales cobran su plena sentido (2012, pp. 166 s., 169). Quizá sea por ello que, ya en lo trabajos fundacionales, ella aparece como el último horizonte del pensamiento antropológico de Tugendhat, y de ahí el título de Egocentricidad y mística. Con ello se aleja el autor de dos actitudes típicamente occidentales: la de tachar de irracional la temática toda de la espiritualidad y la de mantenerse anclado en la propia tradición, sin tomarse la molestia de indagar en las orientales ${ }^{49}$. Ahí radica seguramente la primera dificultad con que tropieza la lectura de la filosofía tugendhatiana de la mística, que es nuestro desconocimiento del fenómeno. Pero aquí no vamos a centrarnos en los abrumadores conocimientos sobre místicas orientales que exhibe el autor, en "tercera persona", sino en las claves de su interpretación filosófica "first personal".

Una segunda dificultad radica en las vacilaciones de Tugendhat, algo que sus lectores conocen ya de sus trabajos sobre el libre albedrío, la honestidad inte-

\footnotetext{
47 En las retractaciones de Probleme der Ethik (1983, pp. 169 ss.); ver Bonete Perales 1990.

48 W. James (1986, pp. 285-322) consideraba los episodios o momentos místicos como "actos de conciencia" de una cualidad enteramente peculiar, pero susceptible de descripción precisa. Tugendhat no articula una caracterización más específica, desde el punto de vista de la filosofía de la mente.

49 Tugendhat 2007a, p. 177 / 2007b, pp. 158 s.
} 
lectual o, sobre todo, la fundamentación de la moral, pero que también sucede, sin mencionarlo expresamente, en sus escritos sobre mística ${ }^{50}$, que son más bien como exploraciones parcialmente diversas. $\mathrm{Y}$ es que Tugendhat no puede evitar reordenar una y otra vez sus propias ideas sobre los temas que le preocupan, que retoca una y otra vez, modificando la clasificación de los fenómenos estudiados o el peso otorgado a este o el otro factor ${ }^{51}$. De ahí que, antes que exponer la serie completa de sus formulaciones o solo la última de las mismas, prefiramos llevar a cabo lo que, en las propias categorías del autor, podemos llamar una interpretación "inmanente" de su pensamiento ${ }^{52}$, señalando, por encima de las modificaciones, en qué direcciones apunta inequívocamente las más de las veces. Con todas estas cautelas, las raíces antropológicas comunes de las diversas corrientes místicas serían las siguientes:

a) La necesidad antropológica, apuntada ya en relación con la pregunta práctica fundamental, de unificarse, concentrarse, recogerse, haciendo patente la propia vida como totalidad limitada por la muerte, frente a la dispersión en los múltiples estados psicológicos y asuntos de la vida.

b) La conciencia unitaria del mundo, o de alguna totalización de la realidad, como el vacío o Dios, en relación con la cual se resitúa el místico, a menudo sintiéndose uno con ello.

c) La correlativa relativización — cuando no su eliminación- de un yo que se siente pequeño ante la totalidad, en relación con el apego excesivo a las propias voliciones, fuente insaciable de la avidez egocéntrica.

d) La paz interior como horizonte práctico último de toda la autoconciencia mística, en relación con la contingencia y la egocentricidad.

Bien se ve que los citados elementos no son recíprocamente independientes, sino que están en interacción: el místico se concentra y unifica (a) en relación con

\footnotetext{
50 Algunos ejemplos: la conciencia de unión con la totalidad que en Raíces aparece como una interpretación incompleta o parcial de las místicas (2002, p. 223), en todos los trabajos siguientes, y particularmente en el último, es una de las claves generales de las mismas (2012, p. 167). Algo similar ocurre con la inmersión (Versenkung) meditativa, que en Egocentricidad resulta demasiado indeterminada y de alcance comparativo solo parcial (2003, p. 116 / 2004, pp. 130 s.), mientras que en Discurso caracteriza o ejemplifica una estructura antropológica general (2007a, pp. 181-183 / 2007b, pp. 162-164).

51 Para una explicación detallada de este modo de proceder en la fundamentación de la moral, Bonet 2017, pp, 675-677.

52 Tugendhat 1967, p. 260; 1979, p. 160; Bonet 1992, pp. 12-20.
} 
la totalidad unitaria (b), ante la cual la conciencia egocéntrica se atenúa, si no desaparece (c), lo que arroja el resultado de la paz interior. Los criterios a los que Tugendhat recurre para clasificar las distintas tendencias místicas son el b) y más aún el c), en ambos casos con la misma consecuencia de colocar al tao y al budismo en casillas alternativas de la mística oriental. A ellas voy a referirme preferentemente. Con respecto a la mística occidental, predominantemente religiosa, Tugendhat solo menciona al Jesús de los evangelios — como una constante, eso sí- y al maestro Eckhart ${ }^{53}$. También pretende, sin ofrecer detalles, que su caracterización sirva igualmente para la mística musulmana. Parece, en todo caso, que su interpretación haya surgido por vía inductiva, por más que no sean pocas las excepciones que habría que hacer constar, sobre todo en relación con b) ${ }^{54}$.

Lo que el punto d) pone de relieve es algo que Tugendhat destaca siempre y que ya Otto presentó como una de las claves de su aproximación, ya clásica, de la mística de Eckhart a la Sankara (Schankara, Çankara): su carácter práctico, no metafísico ${ }^{55}$. Para Otto, se trataba de la salvación (Heil, Otto 1926, pp. 22-37). Para Tugendhat, de "la paz del alma como bien supremo, como único lugar de felicidad constante" (2002, p. 228). De ahí que nuestro autor critique, por ejemplo, las veleidades teóricas del Vedanta, que enmascara — dice- la dirección "propiamente práctica" del movimiento místico (2003, p. 126 / 2004, p. 142). Lejos de ello, las cuatro verdades del budismo justifican el abandono de la avidez (Gier) precisamente porque es la raíz del sufrimiento. Y otro tanto cabe decir del místico taoísta, que proclama igualmente la renuncia a la avidez, aun sin pretender terminar con los deseos o voliciones.

Cuando se habla de mística suele pensarse en el budismo. En él se produce una negación paralela del mundo y de la propia voluntad o el yo. El universo, como totalidad unitaria (ein Eines, die Welt in ibrer Einheit), es visto como un vacío que absorbe la multiplicidad de las cosas. Paralelamente, esta negación del mundo que, de una u otra manera, comparten distintas formas de mística hindú, comporta la disolución del yo y la total renuncia a la voluntad. El interés práctico, que

53 Eckhart 1983, pp. 83-256. Al margen de la mística española, que James 1986 sí que tomara bien en cuenta, a su manera, o de Simone Weil, se echa en falta, por su contenido, la toma en consideración de Underhill 1922, obra singular de mística cristiana inglesa del siglo XIV.

54 Tugendhat no considera la posibilidad de que entre las distintas experiencias místicas, pueda haber, más que un concepto general o común, distintos nexos asociativos (Turner 1999) o parecidos de familia, en el sentido de Wittgenstein.

55 Hasta qué punto esta interpretación de la mística hindú y del budismo se ha convertido en clásica puede comprobarse en Jaspers 2012, pp. 27 s. 
Tugendhat reputa central, es la redención o liberación del sufrimiento que la vida comporta, a causa de las incesantes voliciones (Wollen), ante las cuales el suicidio no representa solución alguna, si existe la reencarnación. Solo la iluminación perfecta que suprime la avidez desembocaría en el Nirvana, sin ya más reencarnaciones. Sin embargo, habiéndose incluso desarrollado un cálculo del número de reencarnaciones que harían falta para ello, las dudas teóricas que nuestro autor quería conjurar, no pueden dejar de aflorar:

Cabe preguntar cómo podía saberse todo esto tan exactamente. Cuesta entender el grado en que esta mística está traspasada de representaciones que a nosotros nos parecen curiosas suposiciones empíricas. (2004, p. 146 / 2003, p. 146)

Tales dudas, en realidad, vienen de antes. Por mucho que Tugendhat destaque, como Otto, el motivo práctico, ¿cómo podría compaginarse una doctrina que suprime el yo o el sí mismo con un planteamiento filosófico que arranca de la egocentricidad humana, y de los deseos y planes de futuro en que ella se plasma (arriba, sección 2)? Cuando el budismo responsabiliza del sufrimiento de la vida animal a la volición, se desentiende por completo del aspecto específico de la voluntad humana de estar vuelta hacia el futuro (2003, pp. 128 / 2004, p. 144). Se comprende, entonces, que Tugendhat simpatice más con la mística taoísta, que no elimina la voluntad específicamente humana, sino que asume su proyección hacia el futuro y la posibilidad de una reflexión sobre el conjunto de la vida. En el Tao, "la voluntad no se desprende de los objetos naturales, sino [que] se relaja" (2002, p. 225), para renunciar a la avidez:

El místico taoísta quiere, como el budista, la paz del alma (Seelenfrieden), pero no fuera de este mundo, sino en él. A diferencia del budista, él no quiere liberar del sufrimiento, sino integrarlo. Su problema no es el sufrimiento, sino el querer o la volición (Wollen), y no el querer en general, sino particularmente aquel que distingue lo específico de la egocentricidad humana (2003, p. 132 / 2004, p. 148).

Es en relación con la egocentricidad y la relajación de la voluntad humana como hay que interpretar, a juicio de Tugendhat, la doctrina taoista del wu-wei, que literalmente significa "no actuar" (Lao-Tse 1971). ¿De qué se trata? De hacer lo que se debe hacer, pero sin exageraciones, sin buscar perdidamente reconocimiento o protagonismo. Se trata de no proponerse metas innecesarias, sino de ver el círculo de la propia actividad lo más pequeño posible. $\mathrm{Y}$ de actuar sin preocupación y sin reparar en uno mismo, prescindiendo de la perspectiva egocéntrica de cómo lo comentarán los otros... En palabras del libro taoísta Chuang Tse: "No busques fama, no construyas esquemas... Aténte a lo que recibiste del cielo, pero no creas 
que posees gran cosa. Vacíate. El hombre perfecto reacciona, pero no se agarra" (cit. en Tugendhat 2002, p. 226). Debido a su necesidad de reconocimiento, a los seres humanos les resulta importante parecer importantes; buscan confirmación y se exhiben ${ }^{56}$. El hombre está enredado consigo y con su voluntad deliberativa. De ahí que, en otro artículo de la serie fundacional, Tugendhat mencione también, a este mismo respecto, la crítica que formula Iris Murdoch, en La soberanía del bien, a cómo nuestras fantasías egocéntricas nos sustraen de la atención a la realidad ${ }^{57}$.

El otro aspecto del Tao que Tugendhat estudia y profundiza, principalmente en Egocentricidad, se relaciona más con la contingencia. Es la doctrina de la unidad de los contrarios, que no se agota en la comparación con Heráclito. Todo en la naturaleza se mueve, sube y baja, en una curva mística en la que los contrarios se copertenecen. Los seres humanos se "ven" subir y bajar, y anticipan lo que sucederá; por ello sufren preocupación (Sorge) y angustia. La reflexión taoísta de segundo grado, considerando la unidad de la curva, permite pacificar el alma.

No se trata de incurrir en el quietismo, sino de aceptar los propios límites a la hora de obrar, de un modo similar al que plantea el "hágase tu voluntad" cristiano. Chuang Tse (Hamill \& Seaton 2000, pp. 78 ss.), habla del Hombre Verdadero -el sabio_- y el Verdadero Conocimiento —el Tao, el camino_-, que consiste en distinguir —y no es fácil— lo que uno mismo puede hacer y lo que hace "el cielo". Por tal se entiende, no una instancia espiritual o supraterrenal, sino una designación para lo que excede el propio poder y los propios planes ${ }^{58}$. Pero ese modo taoísta de enfrentar las pérdidas y desgracias Tugendhat admite que se parece demasiado a la exhortación estoica a apretar los dientes (2007a, p. 200 / 2007b, p. 184).

No es esa la única debilidad que Tugendhat reconoce en el taoísmo, a pesar de simpatizar abiertamente con él. Y es que "en el taoísmo falta el amor. El sabio taoísta es amigable y benevolente, pero reservado y autosuficiente" (2004, p. 160 / 2003, p. 143). Además, cuando ya no se entiende en sentido religioso, ¿cómo habría que entender concretamente la referencia al cielo o al Tao, y la conciencia unitaria del mundo, en relación con la cual se repliega y resitúa el místico? "Tal vez Tao no sea más

56 Hasta aquí, el presente párrafo transcribe, con pocas modificaciones, otro de Bonet 2013, p. 299.

57 "Nietzsche y el problema de la trascendencia inmanente", redactado originalmente en castellano (2002, esp. pp. 210 ss.) y ampliado luego en la versión alemana (2007a, esp. pp. 28 s.).

58 Aportemos una cita: "Cualquiera que haya comprendido la realidad de la vida, no intentará que la vida haga lo que no puede hacer. Cualquiera que haya comprendido la realidad del destino, no intentará que el «conocimiento» cambie lo que no puede cambiarse". (Hamill \& Seaton 2000, p. 151) 
que una palabra retórica" (2004, p. 152 / 2003, p. 136). En Egocentricidad, Tugendhat duda seriamente de que, desaparecido Dios del horizonte místico, sea posible recogerse, sentirse poco importante y alcanzar la paz interior sin referirse a algo (2003, pp. 136-138 / 2004, pp. 152-154). En cambio —uno más—, en Spiritualität, ya no reputa problemática en el Taoísmo la forma en que tiene lugar la auto-relativización del yo, con respecto a una "unitotalidad" (All-Einheit) (2012, p. 168).

En todo caso, en relación con esas debilidades, Tugendhat se inclina cada vez más hacia el budismo Mahayana, sensible a la influencia del Tao, pero también a la visión hinduista del amor. La idea de unidad y mutua compenetración de todas las cosas se traduce en la compasión universal y activa. El bodisatva no puede ignorar las desgracias de los seres humanos. El amor universal desinteresado y altruista, no egocéntrico, de eso que llamamos un corazón bondadoso (Herzensgute), que también nos encontramos en los evangelios, representa la actitud normativa que la moral no puede imponer. Y, no obstante, sería, en opinión de Tugendhat, el motivo que mejor conduciría, a partir de la relativización de sí mismo, a una moral moderna que aúne respeto recíproco y compasión ${ }^{59}$.

Hablamos, en suma, de mística que refrena la identificación con deseos innecesarios, sin descansar en experiencias privilegiadas o sobrenaturales, y que es compatible con la vida ordinaria porque arraiga en estructuras antropológicas universales (Wenning 2017). Y al propio tiempo, la espiritualidad es una actitud no natural —en el sentido de Husserl—, quizá una ida regulativa que encontramos desarrollada en diversas tradiciones, sin que la nuestra sepa hoy muy bien qué hacer con ella (2012, pp. 172 s.).

\section{Preguntas abiertas}

El planteamiento filosófico "first personal" de Tugendhat autoriza, si no exige, que también el lector se posicione en primera persona ante los planteamientos de nuestro filósofo. En mi opinión él ha tenido la valentía de volver la mirada sobre temas religiosos y místicos que no están precisamente de moda en el panorama intelectual. O no lo están, al menos, si se alega que son necesidades antropológicas arraigadas en la contingencia existencial ${ }^{60}$. Es difícil sustraerse al atractivo

\footnotetext{
59 Tugendhat 2003, pp. 143-149 / 2004, pp. 160-165; 2007a, pp. 129-135, 185-189 / 2007b, pp. 110-114, 166-169.

${ }_{60}$ Vattimo 1996 proponía un cierto retorno postmoderno a la religión cristiana expresamente alejado, por ello mismo, de la tensión dramática de la filosofía existencialista.
} 
de su descripción de dicha contingencia y a la pregunta por el modo de vivir en medio de ella, considerada de forma unitaria. En este sentido, me resulta claro y convincente el modo en que Tugendhat presenta los planteamientos heideggerianos sobre el cómo unitario de la vida o su propuesta sobre la necesidad de unificación y recogimiento —en lo cual insistió también la tradición personalista—. Y algo similar cabría decir de su descripción de la oración y otros actos espirituales. Sin embargo, quisiera formular, con brevedad, algunas reservas o interrogantes en relación con su lectura de la mística, la religión y el ateísmo.

En su apertura a las tradiciones orientales, Tugendhat administra, con más frecuencia de la registrada aquí, la muy occidental diferencia entre los planos teórico y práctico. La cuestión, a la que hice ya alguna alusión, se plantea en relación con lo que llamé las raíces antropológicas b) y c) de la mística, es decir, la conciencia unitaria del mundo y la eliminación o relativización del yo. Con respecto a esto último, ya apuntamos que una filosofía de la egocentricidad, si quiere mantener la coherencia, resulta incompatible con cualquier forma de eliminación del yo; y Tugendhat es consciente de ello:

El ideal meditativo de Buda era alcanzar la verdad, que consiste, tal como la entiende él (y como la entenderían casi todas las místicas hindúes), es que, en realidad, no hay nada determinado ni, por consiguiente, nada yoico (2003, p. 145 / 2004, p. 161).

Como una eventual solución para mantener, a pesar de lo dicho, el altruismo del budismo Mahayana, Tugendhat sugiere tímidamente que tratemos las contradicciones de la forma que propone Nagajurna (véase Jaspers 2001, pp. 141 ss.). Olvida, sin embargo, que alguien que trató con tanta dureza la dialéctica hegeliana, por ser incompatible con la lógica formal (Tugendhat 1979, pp. 293 ss.), no puede ahora escaparse por esa tangente sin ofrecer ninguna explicación.

Algo similar ocurre, a mi entender, con el mundo, o el vacío, la totalidad unitaria respecto de la cual el místico no religioso se posiciona y relativiza —o suprime- ya sea en términos de unión mística, o ya sea considerando las cosas y a sí mismo desde la perspectiva de esa unitotalidad. Como ya apunté, resulta más que dudoso que el mundo, entendido como marco espacio-temporal unitario de los objetos que identificamos ordinariamente, pueda desaparecer en el vacío, o pueda unificarse sin referencia ya a ninguna multiplicidad. La única justificación de nuestro autor es que estamos ante una "idea práctica" (2003, p. 146 / 2004, p. 163). ¿Significa esto que carece de importancia cuál sea la idea "teórica”? ¿Quiere decirse que la mística solo es, como a veces parece, una exhortación o meditación moral contra las pretensiones excesivas del yo egocéntrico (2007a, pp. 187-189 / 
2007b, pp. 168-170), o — peor aún— una técnica de relajación que contribuye a relativizarlas? Nuestro autor no llega a plantearse tales preguntas.

Donde Tugendhat no ha aplicado con tanta laxitud esa diferencia de niveles entre lo teórico y lo práctico es en el plano religioso, donde la honestidad intelectual sí impone límites a la idea práctica. Su concepto, tan personal, de religión parte de una matriz individualista y privada que, por ejemplo, lo aleja ab initio del anhelo de justicia evocado, como consustancial al judaísmo, por la escuela de Frankfurt (así en Horkheimer, 2000). Si bien comparte con ella, de alguna manera, la nostalgia por la muerte de Dios: me gustaría, dice Tugendhat, dirigirme a Dios devotamente y pedirle que se haga su voluntad; la honestidad me lo impide — sigue diciendo-, pero me empuja también a reconocer la insuficiencia de una mística impersonal para remediar mis frustraciones (2007a, p. 201 / 2007b, p. 184).

Pero la cuestión más provocativa, la que más comentarios ha suscitado (Jacobi, Hg., 2012), ha sido, sin duda, su impugnación a radice de la fe religiosa y el modo de recusar a cualquiera que no comparta su postura. Una tesis que, de entrada, implica la deshonestidad de cantidades ingentes de filósofos y personas ordinarias. Veamos, por ejemplo, el caso de Thomas Nagel:

...yo mismo padezco fuertemente este temor a la religión, no en sus evidentes efectos perversos en este mundo, sino como visión explicativa universal. Quiero que el ateísmo sea verdadero y me incomoda que algunas de las personas más inteligentes y bien informadas que conozco sean creyentes religiosos. No es sólo que no creo en Dios y que, naturalmente, espero estar en lo correcto en mi creencia. ¡Es que ansío que no exista ningún Dios! No quiero que exista un Dios; no quiero que el universo sea así. (Nagel 2012, p. 144)

Si Tugendhat afirmara únicamente que la existencia de seres espirituales carece de credibilidad en nuestra cultura occidental, no diría nada extraordinario. Mas lo específico de su argumento está en el peso que confiere a los deseos. El suyo, su lamento por no poder creer en Dios, no coincide con el de Nagel, a quien solo le incomoda que haya creyentes inteligentes. ¿Puede decirse, sin más, de todos los creyentes que fue su deseo lo que les llevó a creer? Para responder negativamente, simplemente aduciré dos testimonios de filósofos que me conmueven: el de García Morente, en El hecho extraordinario, y el de Edith Stein. Sugerir que ella fue intelectualmente deshonesta solo puede hacerse por animadversión ideológica. Una sospecha (Thies 2009/2010, p. 340) de la que Tugendhat se ha hecho acreedor.

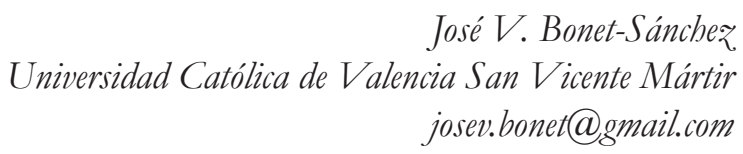




\section{BIBLIOGRAFÍA}

Bergson, H. (2012). Las dos fuentes de la moral y la religión. México: Porrúa.

Bonet, J. V. (1992). Ser, verdad y referencia en la filosofía teórica de Tugendhat, Valencia, Publicaciones de la Universidad de Valencia.

Bonet, J. V. (2013). La pregunta más humana de Ernst Tugendhat. Valencia, Publicaciones de la Univ. de Valencia.

Bonet, J. V. (2017). "Las penúltimas razones de la moralidad en Tugendhat", Revista Isegoría, no 57, pp. 673-690.

Bonete Perales, E. (1990). "E. Tugendhat: un nuevo fundamento de la moral", Éticas contemporáneas, Madrid, Tecnos, pp. 133 ss., esp. 159-168.

Douglas, M. (1998). Estilos de pensar, Barcelona: Gedisa

ECKHART, Maestro (1983). Tratados y sermones, Barcelona: Edhasa.

Hamill, S. \& J. P. Seaton (2000). La sabiduría de Chang-Tsé. Textos fundamentales del Taoísmo, Barcelona: Ediciones Oniro.

Henrich, D. (2006). "Mystik ohne Subjektivität?”, Deutsche Zeitschrift für Philosophie 54 (2), pp. 169-188.

Hermann, U. (2007). “The time for philosophing is over” (entrevista a Tugendhat), Die Tageszeitung, 28-7

Horkheimer, M. (J. J. Sánchez, ed. 2000). Anhelo de justicia. Teoría crítica y religión. Madrid: Trotta.

JacoBi, K. (Hrg.) (2012). Mystik, Religion und intellektuelle Redlichkeit. Nachdenken über Thesen Ernst Tugendhats, Freiburg/München, Verlag Karl Alber.

JAMES, W. (1986). Las variedades de la experiencia religiosa. Barcelona, Península.

JAsPers, K. $\left(2012^{2}\right)$. Los grandes maestros espirituales de Oriente y Occcidente. Buda, Confucio, Laotse, Jesús, Nagarjuna, Agustín (selección de: Die grossen Philosophen). Madrid: Tecnos.

Kenny, A. (1963). Action, Emotion and Will, London, Routledge and Kegan Paul.

NAGEL, T. (2012). La última palabra. Barcelona: Gedisa.

Отто, R. (1926). West-Östliche Mystik. Vergleich und Unterscheidung zur Wesensdeutung.Gotha: Leopold Klotz.

Oтто, R. (2001). Lo santo. Lo racionaly lo irracional en la idea de Dios. Madrid: Alianza.

Perry, J. (1979). "The problem of the essential Indexical", Nous, 13, pp. 13-21.

SCHELEIERmacher, F. (2013). La fe cristiana. Salamanca: Sígueme.

SCHELER, M. (2009). Amor y conocimiento y otros escritos. Madrid: Palabra.

SuÁrez Crothers, M. (2005). "La odisea del filósofo Ernst Tugendhat”, Diálogo Cientifico, 14/1-2, p. 32.

Thies, C. (2009). "Die philosophische Relevanz der Mystik", en C. Thies (Hg.), Religiöse Erfahrung in der Moderne. William James und die Folgen. Wiesbaden, pp. 133-151.

THIEs, C. (2009/2010). "Tugendhats anthropologische Wende”, Internationales Jabrbuch für Philosophische Anthropologie, Bd. 2, pp. 337-342

Todorov, T. (1995). La vida en común, Madrid: Taurus. 
Tugendhat, E. (1967). Der Wabrheitsbegriff bei Husserl und Heidegger, Berlin, W. de Gruyter. Tugendhat, E. (1969). "Heidegger's Idee von Wahrheit", reimp. en G. Skirbekk, Wahrbeitstheorien, Frankfurt, Suhrkamp, 1977, pp. 431-448.

Tugendhat, E. (1970a). "Phänomenologie und Spachanalyse”, en R. Bubner, K. Cramer et al. (eds.), Hermeneutik und Dialektik, vol. 2, Tübingen, Mohr, p. 3-23.

TugEndHAT, E. (1976). Vorlesungen zur Einführung in die sprachanalytische Philosophie, Frankfurt, Suhrkamp [hay traducción española parcial]

Tugendhat, E. (1979). Selbstbewusstsein und Selbstbestimmung, Frankfurt, Surhkamp.

Tugendhat, E. (1984). Probleme der Ethik, Stuttgart, Reclam [hay traducción española].

Tugendhat, E. (1988). Nachdenken über die Atomskriegsgefahr und warum man sie nicht sieht, $2^{\mathrm{a}}$ ed. ampliada, Berlin, Rotbuch.

Tugendhat, E. (1990). "El papel de la identidad en la constitución de la moralidad”, Ideas y valores, no 83-84, Bogotá, p. 3-14.

Tugendhat, E. (1992). Philophische Aufsätže, Frankfurt, Suhrkamp [hay traducción española parcial].

Tugendhat, E. (1993a). Autoconciencia y autodeterminación, Madrid: Fondo de Cultura Económica [traducción española de Tugendhat, 1979].

Tugendhat, E. (1993b). Vorlesungen über Ethik, Frankfurt, Suhrkamp.

Tugendhat, E. (1997). Dialog in Leticia, Frankfurt, Suhrkamp [hay traducción española].

Tugendhat, E. (2002). Problemas. Barcelona, Gedisa.

Tugendhat, E. (2003). Egozentrizität und Mystik, München, C. H. Beck.

Tugendhat, E. (2004). Egocentricidad y mistica. Un estudio antropológico [traducción española de Tugendhat, 2003], Barcelona, Gedisa.

Tugendhat, E. (2005). “Über Selbstbewusstsein: Einige Missverständnisse”, en T. Grundmann, F. Hofmann et al. (Hgs.), Anatomie der Subjektivität. Bewusstsein, Selbstbewusstsein und Selbstgefühl, Frankfurt: Suhrkamp, pp. 247-255.

Tugendhat, E. (2007a). Anthropologie statt Metaphysik [incluye traducción de algunos trabajos de 2002a], München, C. H. Beck. (hay una $2^{\text {a }}$ ed. ampliada de 2010)

Tugendhat, E. (2007b). Antropología en vez de metafísica [traducción española de Tugendhat, 2007 a], Barcelona, Gedisa.

Tugendhat, E. (2012). "Spiritualität, Religion und Mystik", K. Jacobi (Hg., 2012), pp. 161-173.

Tugendhat, E., y U. Wolf (1983). Logisch-semantische Propädeutik, Stuttgart, Reclam.

Turner, V. (1999). La selva de los simbolos. Madrid: Siglo XXI, pp. 65-102.

Underhill, E. (ed.), $\left(1922^{2}\right.$ ). The Cloud of Unknowing (anónimo del siglo XIV). London: John M. Watkins.

VAтtimo, G. (1996). Creer que se cree. Barcelona: Paidós.

Wenning, M. (2017). "Mysticism and Peace of Mind: Reflections on Tugendhat and Daoism", Frontiers of Philosophy in China, 12(4), pp. 554-571. 